\title{
Immune Response and Hemolymph Microbiota of Apis Mellifera and Apis Cerana After the Challenge With Recombinant Varroa Toxic Protein
}

\section{Balachandar Balakrishnan}

Guangdong Institute of Applied Biological Resources

\section{Hua Wu}

Guangdong Institute of Applied Biological Resources

\section{Li Cao}

Guangdong Institute of Applied Biological Resources

\section{Yi Zhang}

Guangdong Institute of Applied Biological Resources

\section{Wenfeng Li}

Guangdong Institute of Applied Biological Resources

\section{Richou Han ( $\nabla$ hanrc@giabr.gd.cn )}

Guangdong Key Laboratory of Animal Conservation and Resource Utilization, Guangdong Public Laboratory of Wild Animal Conservation and Utilization, Guangdong Institute of Applied Biological Resources, Guangdong Academy of Science, Guangzhou 510260, China

\section{Research}

Keywords: Apis mellifera, Apis cerana, Varroa toxic protein, immune response, microbiota

Posted Date: August 26th, 2020

DOl: https://doi.org/10.21203/rs.3.rs-64762/v1

License: (c) (1) This work is licensed under a Creative Commons Attribution 4.0 International License. Read Full License

Version of Record: A version of this preprint was published at Journal of Economic Entomology on April 2nd, 2021. See the published version at https://doi.org/10.1093/jee/toab047. 


\section{Abstract}

Background: The honeybee is a significant crop pollinator and key model insect for understanding social behavior, disease transmission, and development. The ectoparasitic Varroa destructor mite put threats on the honeybee industry. A Varroa toxic protein (VTP) from the saliva of Varroa mites contributes to the toxicity toward Apis cerana and the DWV elevation in Apis mellifera. However, the immune response and hemolymph microbiota of honeybee species after the injection of recombinant VTP has not yet been reported.

Methods: In this study, both $A$. cerana and $A$. mellifera worker larvae were injected with the recombinant VTP. Then the expressions of the honeybee immune genes abaecin, defensin and domeless at three time points were determined by qRT-PCR, and hemolymph microbial community were analyzed by culturedependent method, after recombinant VTP injection.

Results: The mortality rates of $A$. cerana larvae were much higher than those of $A$. mellifera larvae after VTP challenge. VTP injection induced the up-regulation of defensin gene expression in $A$. mellifera larvae, and higher levels of abaecin and domeless mRNAs response in A. cerana larvae, compared with the control (without any injection). PBS injection also upregulated the expression levels of abaecin, defensin, and domeless in A. mellifera and A. cerana larvae. Three bacterial species (Enterococcus faecalis, Staphylococcus cohnii and Bacillus cereus) were isolated from the hemolymph of $A$. cerana larvae after VTP injection and at $48 \mathrm{~h}$ after PBS injections. Two bacterial species (Stenotrophomonas maltophilia and Staphylococcus aureus) were isolated from A. mellifera larvae after VTP challenge. No bacterial colonies were detected from the larval hemolymph of both honeybee species treated by injection only and the control.

Conclusion: The result indicates that abaecin, defensin, and domeless genes and hemolymph microbiota respond to the VTP challenge. VTP injection might induce the dramatic growth of different bacterial species in the hemolymph of the injected larvae of $A$. mellifera and $A$. cerana, which provide cues for further studying the interactions among the honeybee, VTP and hemolymph bacteria.

\section{Background}

The western honeybee Apis mellifera and eastern honeybee Apis cerana are major species in world honeybee industries $[1,2]$. They are wonderful crop pollinators and best model organisms for studying development, behavior, and learning [3]. Ectoparasitic Varroa destructor mite has become one of the greatest threats on apiculture, and an important vector for viral transmission within and between colonies. V. destructor has spread all over the world except Australia within a short time of period [4]. Different viruses have been identified from honeybees, and most of them are carried by Varroa mites. This parasite feeds on the larvae and pupae tissue, clearly representing most sensitive host stage, preferably sealed brood cells [5]. Varroa mites also induce immune suppression in larvae and pupae, and thus are able to initiate the virus infections [6]. The natural host of Varroa mites was A. cerana, which are 
normally not threatened by this mite due to a stable host-parasite bond established over a long evolutionary time anda mixture of the defense systemin $A$. cerana that limits the Varroa population growth $[7,8]$. The new host $A$. mellifera is damaged by Varroa mite and becomes wing deformed by deformed wing virus (DWV) usually carried by the mite. A Varroa toxic protein (VTP) was identified from the saliva of Varroa mites [9]. The recombinant VTP killed $A$. cerana worker larvae and pupae in the absence of DWV, but was safe for $A$. mellifera individuals, and resulted in elevated DWV titers and the subsequent development of deformed-wing adults [9]. However, no information is available on the immune response of the honeybees to the VTP.

Insect symbiotic bacteria can stimulate the immune system of their insect host and thereby raise the efficiency of pathogen defense $[10,11]$. In general, antimicrobial peptides (AMPs) are crucial effectors for insect's innate immune system [12]. Honeybees differ in their ability to protect themselves against $V$. destructorinfestation [13]. Insect gut microbiota are affected by physiological (diet, metabolism, immune system, and gut anatomy) and biological (interactions, transmission, bottlenecks) processes of insects [14]. Gut bacteria play significant roles in health and strength, contribute extremely to host immunity, improve nutrient deficient diets, degrade recalcitrant food ingredients, and protect the host from parasites and pathogens [15-20].

Insect hemolymph is recognized as a key mediator of nutritional and immunological homeostasis and is generally considered to be almost microbe-free in healthy insects [21]. Now more evidence indicates that various non-pathogenic microorganisms can stably or transiently inhabit hemolymph in a diversity of insects [22]. The most-reported hemolymph microorganisms are bacteria of the genus Spiroplasma (Phylum Tenericutes, Family Mollicutes) widely associated with insects in the Hymenoptera, Diptera, Lepidoptera, Hemiptera and Coleoptera orders [23], and members of the Enterobacteriaceae ( $\mathrm{Y}^{-}$ proteobacteria) in aphids, specifically Serratia symbiotica and the sister taxa Hamiltonella defensa and Regiella insecticola $[24,25]$. But hemolymph microbiota in honeybees has not been reported so far.

In this study, the expressed and purified VTP was injected into the 5th stage larvae of $A$. cerana and $A$. mellifera, to determine the immune response and hemolymph microbiota changes of the honeybee larvae at different time intervals.

\section{Materials And Method}

\section{Honeybees and Varroa mites}

A.cerana and A. mellifera colonies were maintained with the standard beekeeping practice in Guangdong Institute of Applied Biological Resource, Guangzhou, China. Freshly capped larvae (the 5th stage) of $A$. mellifera and $A$. cerana were randomly collected from colonies without chalkbrood and foulbrood symptoms according to the published method $[9,26]$. V. destructor mature female mites were collected from worker pupae in $A$. mellifera hives, using a soft camel hairbrush. The hives were not been treated with acaricides. Approximately 20 mites were placed in sterile petri dishes (diameter $=9 \mathrm{~cm}$ ) and used for RNA extraction and bioassays within one hour. 


\section{Virus and microsporidia loads}

Viruses and microsporidia loads were examined from honeybee by RT-PCR amplification using the sequences of 16 bee viruses available from NCBI (acute bee paralysis virus [ABPV], chronic bee paralysis virus [CBPV], deformed wing virus [DWV], Kashmir bee virus [KBV], sacbrood virus [SBV] and Israeli acute paralysis virus [IAPV], black queen cell virus [BQCV], A. mellifera filamentous virus [AmFV], Big Sioux River virus [BSRV], Lake Sinai virus complex [LSV], slow bee paralysis virus [SBPV], $V$. destructor macula-like virus [VdMLV]), cloudy wing virus [CWV], Apis iridescent virus [AIV], Varroa destructor virus 1 [VDV-1], Moku virus [MV] and Chinese Sacbrood Virus [CSBV], together with two microsporidia parasites (Nosema apis and Nosema ceranae). Total RNA was isolated from honeybees, mite saliva and mites using RNAqueous kits (Ambion, Austin, TX, USA) according to the manufacturer's instructions. The PCR reaction mixtures ( $25 \mu \mathrm{L}$ volume in total) containing $4 \mathrm{mM} \mathrm{MgCl}_{2}, 100 \mu \mathrm{M}$ dNTPs, $0.4 \mu \mathrm{M}$ forward and reverse primers (Table 1) [9], 2 units of Taq DNA polymerase (5 U/ $\mu \mathrm{L}$, Sangon Biotech Co., Ltd., Shanghai, China) and $1 \mu \mathrm{L}$ template DNA were performed in a C1000 TM Thermal Cycler PCR system (Bio Rad, Hercules, California, USA) with the following parameters: initial denaturation at $95^{\circ} \mathrm{C}$ for $3 \mathrm{~min}$; followed by 35 cycles of denaturation at $95^{\circ} \mathrm{C}$ for $30 \mathrm{~s}$, annealing at $58^{\circ} \mathrm{C}$ for $30 \mathrm{~s}$, and extension at $60^{\circ} \mathrm{C}$ for $30 \mathrm{~s}$; and a final extension at $72{ }^{\circ} \mathrm{C}$ for $10 \mathrm{~min}$. The amplicons of the expected bands were verified from a $1 \%$ agarose gel and visualized after SYBR green staining with an imaging system (Sagecreation Science co., Beijing, China). The PCR product was purified using a gel extraction kit (Promega, Madison, WI, USA) and subcloned into a pGEM-T Easy Vector (Promega) before transformation into Escherichia coli DH5acompetent cells (Takara, Kyoto, Japan). Five independent positive clones were selected using a bluewhite screen and sequenced in both directions using an Applied Biosystems 3730 automated sequencer (Applied Biosystems, Foster City, CA, USA) at Sangon Biotech Co., Ltd (Shanghai, China). 
Table 1

Primer list for the detection of the viruses and microsporidia

\section{Virus}

1. Deformed Wing Virus (DWV)

che

2. Acute Paralysis Bee Virus (APBV)

\section{Chronic Bee Paralysis Virus} (CBPV)

4. Black Queen Cell Virus (BQCV) Organism Primer sequences
F: GACAAAATGACGAGGAGATTGTT
R: CAACTACCTGTAATGTCGTCGTGTT

F: TTATGTGTCCAGAGACTGTATCCA

R: GCTCCTATTGCTCGGTTTTTCGGT

F: AGTTGTCATGGTTAACAGGATACGAG

R: TCTAATCTTAGCACGAAAGCCGAG

F: TGGTCAGCTCCCACTACCTTAAAC

R: GCAACAAGAAGAAACGTAAACCAC

5. Kashmir Bee Virus (KBV)

F: GATGAACGTCGACCTATTGA

R: TGTGGGTTGGCTATGAGTCA

6. Sacbrood Virus (SBV)

F: GCTGAGGTAGGATCTTTGCGT

R: TCATCATCTTCACCATCCGA

7. ApismelliferaFilamentous Virus (AmFV)

F: CAGAGAATTCGGTTTTTGTGAGTG

R: CATGGTGGCCAAGTCTTGCT

8. Big Sioux River Virus (BSRV)

F: RGTGCAGCTTTATGCGTTGCC

$\mathrm{R}:$

CCGCTGTTGAGAATAAGGATATCCAGG

9. Lake Sinai Virus complex (LSV)

F: GCCWCGRYTGTTGGTYCCCCC

R: GAGGTGGCGGCGCSAGATAAAGT

10. Slow Bee Paralysis Virus (SBPV)

F: GATTTGCGGAATCGTAATATTGTTTG

$\mathrm{R}$ :

ACCAGTTAGTACACTCCTGGTAACTTCG

11. Varroa destructor Macula-like virus (VdMLV)

F: ATCCCTTTTCAGTTCGCT

R: AGAAGAGACTTCAAGGAC

12. Israeli Acute Paralysis Virus (IAPV)

F: AGACACCAATCACGGACCTCAC

R: AGATTTGTCTGTCTCCCAGTGCACAT

13. Cloudy Wing Virus (CWV)
F: ATCAGCGCTTAGTGGAGGAA

R: TCGACAATTTTCGGACATCA
References

(Yang \& CoxFoster 2005)

(Chen et al. 2006)

(Chen et al. 2006)

(Chen et al. 2006)

(Chen et al. 2006)

(Chen et al. 2006)

(Hartmann et al. 2015)

(Charles et al. 2011)

(Ravoet et al. 2013)

(de Mir\&a et al. 2010)

(Parmentier et al. 2015)

(Maori et al. 2009)

(Hong et al. 2011) 


\begin{tabular}{|c|c|c|}
\hline Virus & Organism Primer sequences & References \\
\hline \multirow[t]{2}{*}{ 14. Apis IridescentVirus(AIV) } & $\begin{array}{l}\text { F: } \\
\text { GGCTAGTAAACGTAGTGGATATGACAAT }\end{array}$ & \multirow[t]{2}{*}{$\begin{array}{l}\text { (Chantawannaku } \\
\text { et al. 2006) }\end{array}$} \\
\hline & R: CACCTGGTGGTCCAAGAGAAG & \\
\hline \multirow{2}{*}{$\begin{array}{l}\text { 15. Varroa destructor Virus } 1 \text { (VDV- } \\
\text { 1) }\end{array}$} & R: CTTCCAAGGGCTCATCCATA & \multirow[t]{2}{*}{ (Zioni et al. 2011) } \\
\hline & F: CATGGAAATGGGATCAAACC & \\
\hline \multirow[t]{2}{*}{ 16. Moku Virus (MV) } & F: GTGCGATAGCTAAGCCTGAGATGG & \multirow{2}{*}{$\begin{array}{l}\text { (Mordecai et al. } \\
\text { 2016) }\end{array}$} \\
\hline & R: CAGTGCCCCCTATAGGTGTTGTT & \\
\hline \multirow[t]{2}{*}{ 17. Chinese Sacbrood Virus (CSBV) } & F: CCTGGGAAGTTTGCTAGTATTTACG & \multirow[t]{2}{*}{ (Chen et al. 2006) } \\
\hline & R: CCTATCACATCCATCTGGGTCAG & \\
\hline \multirow[t]{2}{*}{ 18.Nosema.apis } & F: CCATTGCCGGATAAGAGAGT & \multirow[t]{2}{*}{ (Li et al. 2012) } \\
\hline & R: CCACCAAAAACTCCCAAGAG & \\
\hline \multirow[t]{2}{*}{ 19.Nosema.ceranae } & F: GACAACAAGGAAGACCTGGAAGTG & \multirow[t]{2}{*}{ (Li et al. 2012) } \\
\hline & $\begin{array}{l}\text { R: } \\
\text { TGTGAATAAGAGGGTGATCCTGTTGAG }\end{array}$ & \\
\hline
\end{tabular}

\section{Larvae injection with recombinant VTP}

VTP gene was obtained from the Varroa mites, and the expression and purification of recombinant VTP were conducted as previously described [9]. The purified recombinant VTP was injected into the 5th stage larvae according to the described method [9]. Briefly, a $0.2-\mu \mathrm{L}$ aliquot of the purified recombinant-VTP at a concentration of $0.2 \mu \mathrm{g} / \mathrm{mL}$ was injected into the hemocoel of an $A$. mellifera or $A$. cerana larva near the end of the abdomen, by using pulled glass capillary needles in conjunction with a Harvard micro-injector system (IM-31, Narishige, Tokyo, Japan). Negative controls, such as uninjected bees (= CK) and bees injected with only sterile PBS (= PBS) or only the needle puncture, were established, with 3 replicates per each treatment.

After injection, larvae were reared in 48 well culture plates under regulated conditions $(34 \pm 1 \circ \mathrm{C}$ temperature, $80 \%$ relative humidity and $16 \mathrm{~h}$ light $/ 8 \mathrm{~h}$ dark photoperiod) without microbial infection and bled larvae were discarded. From each treatment, 10 live larvae were randomly collected 12, 24 or $48 \mathrm{~h}$ post-treatment, frozen in liquid nitrogen and stored at $-80^{\circ} \mathrm{C}$ for RNA extraction.

\section{Expression profile of larval immune genes after VTP injection}

Three immune genes (abaecin, domeless and defensin) were used to evaluate the immune response of the injected larvae by using qRT-PCR with the primers in Table 2. Housekeeping $\beta$-actin gene was used in the internal reference to normalize the target gene expression. Each reaction ( $20 \mu \mathrm{L}$ volume $)$ contained 
$1 \mu \mathrm{L}$ (10 ng) cDNA template, $0.8 \mu \mathrm{L} 10 \mu \mathrm{M}$ forward/reverse primers, $10 \mu \mathrm{L} 2 \mathrm{X}$ FastStart Essential DNA Green Master $^{\mathrm{TM}}$ (Roche, Shanghai, China) and 7.4 $\mu \mathrm{L}$ RNase-free water. qRT-PCR was performed on a Rotor Gene Q Real Time Thermal Cycler (Qiagen, Hilden, Germany) with the following parameters: initial denaturation for one cycle at $95^{\circ} \mathrm{C}$ for $10 \mathrm{~min}$, followed by 40 cycles at $95^{\circ} \mathrm{C}$ for $15 \mathrm{~s}$, and $60^{\circ} \mathrm{C}$ for $30 \mathrm{~s}$. The qRT-PCR was repeated three times, and the independent RNA sample preparation consisted of three technical replicates.

Table 2

Primers used for VTP gene and qRT-PCR of the immune genes in this study.

\begin{tabular}{|lll|}
\hline Primer Name & Primer sequences 5'- $\mathbf{3}^{\prime}$ & Application \\
\hline VTP-F & GAATTCATGTTCAAACTTCTCGTTATCG & Protein expression \\
\hline VTP-R & AAGCTTTTAGGAGGCGAGCGCCTGCTGGA & qRT-PCR \\
\hline Abaecin-F & CAGCATTCGCATACGTACCA & \\
\hline Abaecin-R & GACCAGGAAACGTTGGAAAC & qRT-PCR \\
\hline Defensin-F & GTTGAGGATGAATTCGAGCC & \\
\hline Defensin-R & TTAACCGAAACGTTTGTCCC & qRT-PCR \\
\hline Domeless-F & TTGTGCTCCTGAAAATGCTG & qRT-PCR Reference gene \\
\hline Domeless-R & AACCTCCAAATCGCTCTGTG & \\
\hline B-Actin-F & GCCCAATCCAAAAGAGGTAT & \\
\hline B-Actin -R & TCAAAGGTGCTTCCGTTAGT & \\
\hline Obiota analysis of the lanal hemolymph after VTP \\
\hline
\end{tabular}

The A. mellifera and A.cerana live larvae were collected after 12, 24 or $48 \mathrm{~h}$ post-treatments of VTP injection, PBS injection, injection only (needle puncture) or control (without any treatment). Prior to honeybee larvae dissection, the larvae were disinfected to remove external microbes with $75 \%$ ethanol and then rinsed 3 times with sterile ultra-pure water [17]. The larval abdomen was faced up in a sterile petri plate. After a small hole was carefully made using a sterile sharp-billed tweezers, the hemolymph (usually 30-60 $\mu \mathrm{L}$ from each larva) was collected with a pipette in a sterile tube. Three replicates with 10 larvae for each replicate were established for each treatment. The collected hemolymph was spread using the sterile L-rod onto the plates (diameter $=9 \mathrm{~cm}$ ) respectively containing five growth media: TSA (tryptone $15 \mathrm{~g}$, peptone $5 \mathrm{~g}, \mathrm{NaCl} 5 \mathrm{~g}$, agar $15 \mathrm{~g}$, $1 \mathrm{~L}$ distilled water, pH 7.2; TSA + 5\% Sheep serum (TSA medium was heated evenly, then cooled to about $50{ }^{\circ} \mathrm{C}$, and $5 \mathrm{ml}$ of sterilized decalcified sheep serum (Sigma-Aldrich, Germany) were added into $100 \mathrm{~mL}$ TSA medium); HIA (Heart Infusion Agar) (Beef heart infusion $10 \mathrm{~g}$, tryptone $10 \mathrm{~g}, \mathrm{NaCl} 5 \mathrm{~g}$, agar $15 \mathrm{~g}$, and $1 \mathrm{~L}$ distilled water; PDA (Potato Dextrose Agar) (Potato $200 \mathrm{~g}$, sucrose $20 \mathrm{~g}$, agar $15 \mathrm{~g}$ and $1 \mathrm{~L}$ distilled water, pH 6.0;Gaoshi No.1 (Soluble starch 
$20 \mathrm{~g}, \mathrm{KNO}_{3} 1 \mathrm{~g}, \mathrm{~K}_{2} \mathrm{HPO}_{4} 0.5 \mathrm{~g}, \mathrm{MgSO}_{4} \cdot 7 \mathrm{H}_{2} \mathrm{O} 0.5 \mathrm{~g}, \mathrm{NaCl} 0.5 \mathrm{~g}, \mathrm{FeSO}_{4} \cdot 7 \mathrm{H}_{2} \mathrm{O} 0.01 \mathrm{~g}$, agar $15 \mathrm{~g}$ and distilled water $1 \mathrm{~L}, \mathrm{pH} 7.4)$. The plates were incubated respectively in anaerobical $\left(5 \% \mathrm{CO}_{2}\right)$ and aerobical conditions at $36^{\circ} \mathrm{C}$ and $80 \%$ relative humidity for 2 days. Bacterial colonies grew on different media plates (no fungal colonies were detected) were selected based on size, color, and morphology. The selected colonies were repeatedly streaked individually on fresh LB agar plates to obtain pure bacterial cultures. The resulting colonies were cultured in liquid LB and kept at $-80^{\circ} \mathrm{C}$ with $15 \%$ glycerol.

To identify the bacterial isolates from the plates, genomic DNA of each isolate was extracted, and bacterial $16 \mathrm{~S}$ rRNA gene was amplified with the general bacterial primers $28 \mathrm{~F} 5$ -

GAGTTTGATCNTGGCTCAG-3' and1392R 5'-ACGGGCGGTGTGTRC-3' [27, 28]. The PCR mixture contained $5 \mu \mathrm{L}$ of $10 \times$ Pfu buffer, $4 \mu \mathrm{L}$ of dNTP mixture $(2.5 \mathrm{mM}), 1 \mu \mathrm{L}$ of eachprimer $(10 \mu \mathrm{M}), 2 \mu \mathrm{L}$ of deionized formamide, $1 \mu \mathrm{L}$ of $\mathrm{MgCl} 2(25 \mathrm{mM}), 1 \mu \mathrm{L}$ of genomic DNA, and0.5 $\mu \mathrm{L}$ of Pfu DNA polymerase in a total volumeof $50 \mu \mathrm{L}$. PCR amplification was performed in aTGradient thermocycler (Applied Biosystems). The PCR condition was $10 \mathrm{~min}$ at $95^{\circ} \mathrm{C}$, followed by 25 cycles of denaturation at $95^{\circ} \mathrm{C}$ for $30 \mathrm{~s}$, annealing at $55^{\circ} \mathrm{C}$ for $45 \mathrm{sec}$, and $2 \mathrm{~min}$ for elongation at $72{ }^{\circ} \mathrm{C}$; and a final extension step of $72{ }^{\circ} \mathrm{C}$ for $10 \mathrm{~min}$. PCR products of different bacterial isolates were sequenced by Sangon Biotech Co., Ltd., (Shanghai, China).The resulting sequences were compared with the data set in NCBI GenBank.

\section{Data analysis}

The relative value of the gene expression was analyzed by the comparative CT method (2区 $\left.{ }^{\Delta \Delta C T}\right)$ [29]. All the graphs were performed using Prism 6.0 for Windows (GraphPad, La Jolla, CA, USA, www.graphpad.com). Percentage data were arcsine square-root transformed prior to statistical analysis by one-way ANOVA with SPSS 16.0 software (SPSS Inc., Chicago, IL, USA). Means were separated using Tukey's test. Differences among means were considered significant at $P<0.05$.

\section{Results}

\section{Virus occurrence from the larvae}

No visible clinical symptoms or pathogen colonies (such as American foulbrood or chalkbrood) were found in the honeybee larvae. For the detection of 17 viruses and 2 microsporidia parasites in the larvae, the RT-PCR was conducted according to the primers in Table 1.DWV, BQCV, CWV, and MV were detected from more than $60 \%$ of the checked larvae of $A$. mellifera (Table 3). LSV and SBV were detected from most of the $A$. cerana larvae. Interestingly, the most common virus for $A$. mellifera and $A$. cerana was IAPV, which was detected from both honeybee species (Table 3). 
Table 3

Viruses from A. mellifera (A) and A. cerana (B) larvae

\section{Virus Name}

1. Deformed Wing Virus (DWV)

2. Acute Paralysis Bee Virus (APBV)

3. Chronic Bee Paralysis Virus (CBPV)

4. Black Queen Cell Virus (BQCV)

5. Kashmir Bee Virus (KBV)

6. Sacbrood Virus (SBV)

7. Apis mellifera Filamentous Virus (AmFV)

8. Big Sioux River Virus (BSRV)

9. Lake Sinai Virus complex (LSV)

10. Slow Bee Paralysis Virus (SBPV)

11. Varroa destructor Macula-like virus (VdMLV)

12. Israeli Acute Paralysis Virus (IAPV)

13. Chinese Sacbrood Virus (CSVB)

14. Cloudy Wing Virus (CWV)

15. Apis Iridescent Virus

16. VDV1

17. Moku Virus (MV)

18. Nosemaapis

19.N.ceranae

Virus Name

1. Deformed Wing Virus (DWV)

2. Acute Paralysis Bee Virus (APBV)

Animal Animal Animal

1

$+$

2

$+$

$+$

$+\quad+\quad+$

3

Animal Animal5 4

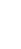




$\begin{array}{llllll}\text { Virus Name } & \text { Animal } & \text { Animal } & \text { Animal } & \text { Animal } & \text { Animal5 } \\ & 1 & 2 & 3 & 4 & \end{array}$

3. Chronic Bee Paralysis Virus (CBPV)

4. Black Queen Cell Virus (BQCV) +

5. Kashmir Bee Virus (KBV)

6. Sacbrood Virus (SBV) $+$

7. Apis mellifera Filamentous Virus (AmFV)

8. Big Sioux River Virus (BSRV)

9. Lake Sinai Virus complex (LSV)

$+$

10. Slow Bee Paralysis Virus (SBPV)

11. Varroa destructor Macula-like virus (VdMLV)

12. Israeli Acute Paralysis Virus

13. Chinese Sacbrood Virus(CSVB) $+$

$+$


seemed that VTP challenge significantly decreased the survival rates of $A$. cerana larvae but did not influence the mortality rates of $A$. mellifera larvae.

\section{VTP protein expression and purification}

The full-length VTP sequence from $V$. destructor mite consisted of 952 base pairs and contained 405 open reading frame (ORF) nucleotides encoding a 134 amino acid polypeptide. The predicted molecular mass of the VTP amino acid sequence was $14.6 \mathrm{kDa}$, and predicted theoretical isoelectric point (PI) 5.27, in accordance with previously published results [9]. The recombinant plasmid pET-28a-VTP transformants were expressed in E. coli BL21 (DE-3) cells. The expression of the recombinant protein was induced by IPTG under growth conditions of $25^{\circ} \mathrm{C}$ (Fig. 2). The expected bands were detected at approximately $30 \mathrm{kDa}$. The fusion protein was purified with a $\mathrm{Ni}^{2+}-\mathrm{NTA}$ agarose gel column and reexamined using a $12 \%$ SDS-PAGE gel. The purified protein (>95\% purity) of VTP showed the estimated molecular weight of a single band (Fig. 2).

\section{The expression profiles of immune genes}

The expression patterns of abaecin, domeless and defensin genes in the challenged to A. mellifera and $A$. cerana larvae were obtained after $12 \mathrm{~h}, 24 \mathrm{~h}$, and $48 \mathrm{~h}$ by qRT-PCR (Fig. 3A-F).In response to VTP injection, the expression patterns of abaecin in A. mellifera larvae showed no significant changes among the treatment and the controls. The transcript level of abaecin gene was the highest expression level after 12,24 , and $48 \mathrm{~h}$ of PBS injection (Fig. 3A). The mRNA level of defensin gene was significantly higher at $12 \mathrm{~h}$ than that at $24 \mathrm{~h}(F=3.133, P=0.275, F=4.164, P=0.330)$ after VTP injection, but decreased at $48 \mathrm{~h}$ treatment (Fig. 3B). Compared to the controls, the mRNA levels of domeless gene expression did not significantly differ at three time points after VTP injection in $A$. mellifera larvae. Meanwhile, the mRNA level of domeless gene expression at $12 \mathrm{~h}$ after PBS injection was highly $(F=14.062, P=0.296)$ expressed in A. mellifera larvae (Fig. 3C).

In the $A$. cerana larvae, the abaecin transcript was highly up-regulated at $24 \mathrm{~h}$ after VTP injection ( $F=$ $6.093, P=0.363 ; F=0.163, P=0.214)$, and at $48 \mathrm{~h}$ after puncture injection or at $12 \mathrm{~h}$ after PBS injection (Fig. 3D and 3F). The defensin mRNA level of the A. cerana larvae was significantly higher at $12 \mathrm{~h}$ and $48 \mathrm{~h}$ after PBS injection, but no significant differences in the defensin mRNA levels were found from the larvae challenged with VTP and the controls (Fig. 3E). The domeless expressions were significantly upregulated at $12 \mathrm{~h}$ after puncture injection, at 12 and $48 \mathrm{~h}$ after PBS injection, or at $24 \mathrm{~h}$ after VTP injection, but down-regulated at $48 \mathrm{~h}$ after VTP injection compared with the controls (no injection, puncture injection, and PBS injection). So the purified recombinant VTP could increase or decrease the expression levels of abaecin, defensin and domeless genes at different time intervals, suggesting that the VTP might be involved in the response of honeybee immune genes.

\section{The changes in hemolymph microbiota of the larvae after VTP injection}


The hemolymph microbial community from the $A$. mellifera and $A$. cerana larvae were analyzed by the culture-based method. From the colonies clearly identical in size, color, and morphology, five representative bacterial species were selected and identified from the VTP injected larvae of $A$. mellifera and A. cerana, based on 16S rRNA sequences (Fig. 4). Three bacterial species (Enterococcus faecalis, Staphylococcus cohnii and Bacillus cereus) were isolated from TSA or HIA plates in both anaerobic and aerobic conditions from the hemolymph of $A$.cerana larvae at three time points after VTP injection and at $48 \mathrm{~h}$ after PBS injections. Two bacterial species (Stenotrophomonas maltophilia and Staphylococcus aureus) were isolated on HIA and TSA plates under aerobic and anaerobic conditions from A. mellifera larvae at three time points after VTP injection. No bacterial colonies were detected on any plates from the larval hemolymph of both honeybee species treated by injection only and the control (without any injection). The loads of these bacterial species were variable from 1 to over 200 colonies on a plate. The results indicated that VTP injection induced the growth of $S$. maltophilia and $S$. aureusin the hemolymph of the injected $A$. mellifera larvae, and VTP or PBS injection stimulated the bacterial growth of $E$. faecalis, $S$. cohnii and $B$. cereus in the hemolymph of the injected larvae in A.cerana.

\section{Discussion}

Honeybees are infected by different pathogens such as viruses and Varroa mite. In this study, more virus species were detected from $A$. mellifera larvae than those in $A$. cerana larvae. Multiple virus infections were common in both honeybee species. The occurrence of DWV, BQCV, CWV, MV and IAPV in A. mellifera has been reported in several studies [30-32]. The higher virus prevalence in $A$. mellifera than in A. cerana suggested that the western honeybees potentially act as carriers of honeybee viruses. The present results also confirmed that VTP injection killed the larvae of $A$. cerana, which was reported by Zhang et al. (2018).

Four known pathways such as the transmembrane signal transducing pathway (Toll), immune deficiency (Imd), Janus kinase/signal transducers and activators of transcription (JAK/STAT), and intracellular signaling pathways (JNK) are involved in the inducible defense of honeybee [33]. The expression patterns of abaecin, defensin and domeless genes induced by VTP injection, PBS injection and injection only were determined by qRT-PCR at three time intervals. VTP injection induced the defensin response in $A$. mellifera larvae, and abaecin and domeless response in $A$. cerana larvae, compared with the control. PBS injection also induced abaecin, defensin, and domeless response in A. mellifera and $A$. cerana larvae. These results contradicted the finding of abaecin and defensin suppression by Varroa mite during bee development [34] and are more constant with the report that specific honeybee immune genes were upregulated in developing brood during Varroa parasitism $[35,36]$.

Five core bacterial species (Snodgrassella alvi, Gilliamella apicola, Lactobacillus Firm-4ロFirm-5, Bifidobacterium) and four other bacterial species (Frischella perrara, Bartonella apis, Parasaccharibacter apium, and Gluconobacter) were found from the gut of honeybees by culture-dependent and independent methods [37-40]. Compared with the core species, four other species were less abundant and unstable in the gut of honeybees. The bacterial community was influenced by the quarantine disease American 
foulbrood caused by Paenibacillus larvae spores in the worker bee [41], and by the parasite $V$. destructor and pathogens Nosema and Lotmaria passimin adult bees [42]. Although gut microbiota was not studied in this paper, E. faecalis, S.cohnii and B. cereus from the hemolymph of A.cerana larvae, and $S$. maltophilia and $S$. aureus from the hemolymph of $A$. mellifera larvae were for the first time detected after these larvae were injected with purified recombinant VTP. However, no bacterial colonies were found from the larval hemolymph of both honeybee species treated by injection only and the control without any injection. These results indicated that different bacterial species were active in the hemolymph of both honeybee species and VTP injection stimulated the bacterial growth in the larval hemolymph. How the bacteria existed in the hemolymph remained unclear. It seemed impossible that these bacteria were introduced into the hemolymph by the injection itself because no bacteria were detected from the larvae challenged by injection only. Maybe the loads of these hided bacteria in the hemolymph of the control larvae were too low to be detected by the present culture method.

E. faecalis, S. cohnii and B. cereus were isolated from the hemolymph of $A$. cerana larvae in the present study. Surprisingly, apart from VTP, sterile PBS injection also induced the bacterial loads in the larval hemolymph. It seemed that bacteria in the hemolymph of $A$. cerana larvae are sensitive to overgrow by foreign materials. E. faecalis was reported from A. mellifera [41, 43]. S. cohnii and B. cereus were also isolated from A. mellifera honeybee [44]. However, it was uncertain that these bacterial species were associated with the hemolymph of $A$. mellifera honeybee. The bacteriocin-producing $E$. faecalis was tested against different spoilage and pathogenic micro-organisms, including Paenibacillus larvae [45]. Paenibacillus larvae infection enriched the abundance of $E$. faecalis in the whole worker bee [41]. As a bio-control agent, $B$. cereus from honey samples and other apiarian sources was used to inhibit the bacterium $P$. larvae in $A$. mellifera bees [46]. Whether mite infection induced increasing $E$. faecalis and/or $B$. cereus loads to inhibit $P$. larvae disease in the hemolymph needs further study.

S. maltophilia and S. aureus were found from the hemolymph of $A$. mellifera larvae. This was the first record of $S$. maltophilia isolated from the honeybees. However, this species resides in a broad range of environments and are commonly identified only as multidrug-resistant opportunistic pathogens of humans [47], in soils or in association with plants [48], and also associated with multiple insect species, including the diamondback moth Plutella xylostella [49], the red turpentine beetle Dendroctonus valens [50], the twelve-toothed pine bark beetle Ips sexdentatus [51], the asian malaria mosquito Anopheles stephensi [52], the peach fruit fly Bactrocera zonata [53], the muga silkworm Antheraea assamensis [54] and the wings of the Colorado potato beetle Leptinotarsa decemlineata [55]. S. maltophilia was also isolated from the honeydew of Indian lac insect Kerria lacca [56] and from the stable fly Stomoxys calcitrans larvae presenting antifungal activity against Beauveria bassiana [57]. Furthermore, $S$. maltophilia associated with Delia antiqua larvae can inhibit $B$. bassiana infection [58]. The functions of $S$. maltophilia in the hemolymph of $A$. mellifera honeybees upon VTP induction should be an interesting topic for further investigation. $S$. aureusis a human wound pathogen which can be counteracted by lactic acid bacterial symbionts in honeybees [59]. However, this bacterial species was also detected from the digestive gut of adult worker honeybees [60]. Why this species also existed in the larval hemolymph of $A$. mellifera bees remains unknown. 


\section{Conclusion}

In summary, in this study VTP injection induced the response of the immune genes (abaecin, defensin and domeless) and the changes of the hemolymph microbiota of $A$. mellifera and $A$. cerana larvae. The mortality rates of $A$. cerana larvae were much higher than those of $A$. mellifera larvae after VTP challenge. Three bacterial species (Enterococcus faecalis, Staphylococcus cohnii and Bacillus cereus) and two bacterial species (Stenotrophomonas maltophilia and Staphylococcus aureus) were for the first time detected from the hemolymph of $A$. cerana and $A$. mellifera larvae after VTP injection, respectively.

\section{Abbreviations}

VTP

Varroa toxic protein; DWV:Deformed wing virus; PBS:Phosphate-buffered saline; qRT-PCR:Quantitative real time-polymerase chain reaction; HIA:Heart infusion agar; TSA:Tryptone soy agar; PDA:Potato dextrose agar

\section{Declarations}

\section{Acknowledgements}

We thank those who help us in sample collection and technical assistance.

\section{Author Contribution}

$\mathrm{RCH}, \mathrm{YZ}$ and WFL designed and coordinated the research. BB, HW and LC conducted the research. BB analyzed the data. $\mathrm{BB}$ and $\mathrm{RCH}$ wrote the manuscript. All authors approved the final version of the manuscript.

\section{Funding}

This study was supported GDAS Project of Science and Technology Development (2019GDASYL0103061).

\section{Availability of data and materials}

All data generated or analyzed during this study are available from the corresponding author upon reasonable request.

\section{Consent for publication}

Not applicable.

\section{Competing interests}


The authors declare no conflict of interest.

\section{References}

1. Gallai N, Salles J-M, Settele J, Vaissière BE. Economic valuation of the vulnerability of world agriculture confronted with pollinator decline. Ecol Econ. 2009;68:810-21.

2. Garibaldi LA, Steffan-Dewenter I, Kremen C, Morales JM, Bommarco R, Cunningham SA, et al. Stability of pollination services decreases with isolation from natural areas despite honey bee visits. Ecol Lett. 2011;14:1062-72.

3. Brutscher LM, Michelle L,Flenniken. RNAi and antiviral defense in the honey bee. J. Immunol. Res. 2015.

4. Rosenkranz P, Aumeier P, Ziegelmann B. Biology and control of Varroa destructor. J Invertebr Pathol. 2010;103:96-119.

5. Ramsey SD, Ochoa R, Bauchan G, Gulbronson C, Mowery JD, Cohen A, et al. Varroa destructor feeds primarily on honey bee fat body tissue and not hemolymph. Proc. Natl. Acad. Sci. 2019;116:17921801.

6. Yang X, Cox-Foster D. Effects of parasitization by Varroa destructor on survivorship and physiological traits of Apis mellifera in correlation with viral incidence and microbial challenge. Parasitology. 2007;134:405-12.

7. Peng Y-S, Fang Y, Xu S, Ge L. The resistance mechanism of the Asian honey bee, ApisceranaFabr., to an ectoparasitic mite, Varroa jacobsoniOudemans. J Invertebr Pathol. 1987;49:54-60.

8. Oldroyd BP. (1999). Coevolution while you wait: Varroa jacobsoni, a new parasite of western honeybees. Trends Ecol.Evol. 1999;14:312-315.

9. Zhang Y, Han R. A saliva protein of Varroa mites contributes to the toxicity toward Apis cerana and the DWV elevation in A. mellifera. SciRep. 2018;8:1-9.

10. Evans JD. Beepath: an ordered quantitative-PCR array for exploring honeybee immunity and disease. J Invertebr Pathol. 2006;93:135-9.

11. De Souza DJ, Bézier A, Depoix D, Drezen J-M, Lenoir A. Blochmannia endosymbionts improve colony growth and immune defence in the ant Camponotus fellah. BMC Microbiol. 2009;9:29.

12. Wu Q, Patocka J, Kuca K. Insect antimicrobial peptides, a mini review. Toxins. 2018;10:461-78.

13. Rinderer TE, Danka RG, Johnson S, Bourgeois L, Frake AM, Villa JD. Functionality of varroa-resistant honey bees (Hymenoptera: Apidae) when used for western U.S. honey production and almond pollination. J Econ Entomol. 2014;107:523-30.

14. Bonilla-Rosso G. Philipp Engel. Functional roles and metabolic niches in the honey bee gut microbiota. CurrOpinMicrobiol. 2018;43:69-76.

15. Dillon RJ, Dillon VM. The gut bacteria of insects: nonpathogenic interactions. Ann Rev Entomol. 2004;49:71-92. 
16. Mazmanian SK, Liu CH, Tzianabos AO, Kasper DL. An immune modulatory molecule of symbiotic bacteria directs maturation of the host immune system. Cell. 2005;122:107-18.

17. Engel P. MoranNA.. T Functional and evolutionary insights into the simple yet specific gut microbiota of the honey bee from metagenomic analysis. Gut Microbes. 2013;4:1-6.

18. Rooks MG, Garrett WS. Gut microbiota, metabolites and host immunity. Nat Rev Immunol. 2016;16:341-52.

19. Lee FJ, Miller KI, McKinlay JB, Newton IL. Differential carbohydrate utilization and organic acid production by honey bee symbionts. FEMS Microbiol Ecol. 2018;94:fiy113.

20. Tomasova L, Konopelski P, Ufnal M. Gut bacteria and hydrogen sulfide: the new old players in circulatory system homeostasis. Molecules. 2016;21:1558.

21. Lemaitre B, Jules Hoffmann. The host defense of Drosophila melanogaster. Annu. Rev Immunol. 2007;25:697-743.

22. Blow F, Douglas AE. The hemolymph microbiome of insects. J Insect Physiol. 2019;115:33-9.

23. Herren, Jeremy K, Juan C, Paredes F, Schüpfer K, Arafah P, Bulet, et al. Insect endosymbiont proliferation is limited by lipid availability. Elife 3. 2014;e02964.

24. Henry LM, Peccoud J, Simon JC, Hadfield JD, Maiden MJ, Ferrari J, et al. Horizontally transmitted symbionts and host colonization of ecological niches. Curr Biol. 2013;23:1713-7.

25. Zytynska SE, Meyer ST, Sturm S, Ullmann W, Mehrparvar M, Weisser WW. Secondary bacterial symbiont community in aphids responds to plant diversity. Oecologia. 2016;180:735-47.

26. Kanbar G, Engels W. Ultrastructure and bacterial infection of wounds in honey bee (Apis mellifera) pupae punctured by Varroa mites. Parasitol Res. 2003;90:349-54.

27. Mattila HR, Rios D, Walker-Sperling VE, Roeselers G, Newton IL. Characterization of the active microbiotas associated with honey bees reveals healthier and broader communities when colonies are genetically diverse. PLoSONE. 2012;3:e32962.

28. Moran NA, Hansen AK, Powell JE, Sabree ZL. Distinctive gut microbiota of honey bees assessed using deep sampling from individual worker bees. PLoSONE. 2012;7:e3639.

29. Livak KJ, Schmittgen TD. Analysis of relative gene expression data using real-time quantitative PCR and the $2-\Delta \Delta$ CT method. Methods. 2001;25:402-8.

30. Ai H, Yan X, Han R. Occurrence and prevalence of seven bee viruses in Apis mellifera and Apis cerana apiaries in China. J Invertebr Pathol. 2012;109:160-4.

31. Carreck NL, Ball BV, Martin SJ. Honey bee colony collapse and changes in viral prevalence associated with Varroa destructor. J Apic Res. 2010;49:93-4.

32. Mordecai GJ, Brettell LE, Pachori P, Villalobos EM, Martin SJ, Jones IM, et al. Moku virus; a new Iflavirus found in wasps, honey bees and Varroa. Sci Rep. 2016;6:34983.

33. Cizelj I, GordanaGlavan J, Božič I, Oven V, Mrak MojcaNarat. "Prochloraz and coumaphos induce different gene expression patterns in three developmental stages of the Carniolan honey bee (Apis mellifera carnica Pollmann). Pestic Biochem Phys. 2016;128:68-75. 
34. Gregory PG, Evans JD, Rinderer T, de Guzman L. Conditional immune-gene suppression of honeybees parasitized by Varroa mites. J Insect Sci. 2005;5:7.

35. Aronstein KA, Saldivar E, Vega R, Westmiller S, Douglas AE. How Varroa parasitism affects the immunological and nutritional status of the honey bee, Apis mellifera. Insects. 2012;3:601-15.

36. Gregorc A, Evans JD, Scharf M, Ellis JD. Gene expression in honey bee (Apis mellifera) larvae exposed to pesticides and Varroa mites (Varroa destructor). J Insect Physiol. 2012;58:1042-9.

37. Babendreier D, Joller D, JörgRomeis F, Bigler, Widmer F. Bacterial community structures in honeybee intestines and their response to two insecticidal proteins. FEMS Microbiol Ecol. 2007;59:600-10.

38. Bottacini F, Milani C, Turroni F, Sánchez B, Foroni E, et al. Bifidobacterium asteroides PRL2011 genome analysis reveals clues for colonization of the insect gut. PLoSONE. 2012;7:e44229.

39. Kwong WK, Moran NA. Gut microbial communities of social bees. Nat Rev Microbiol. 2016;14:37484.

40. Donaldson GP, Lee SM, Mazmanian SK. Gut biogeography of the bacterial microbiota. Nat Rev Microbiol. 2016;14:20-32.

41. Erban T, OndrejLedvinka M, Kamler M, Nesvorna BronislavaHortova, et al. Honeybee (Apis mellifera)associated bacterial community affected by American foulbrood: detection of Paenibacillus larvae via microbiome analysis.Sci. Rep. 2017;7:1-10.

42. Hubert J, Bicianova M, OndrejLedvinka M, Kamler PJ, Lester, et al. Changes in the bacteriome of honey bees associated with the parasite Varroa destructor, and pathogens Nosema and Lotmaria passim. Microb. Ecol. 2017;73:685-98.

43. Gaggia F, Baffoni L, Stenico V, Alberoni D, Buglione E, Lilli A, Porrini C. Microbial investigation on honey bee larvae showing atypical symptoms of European foulbrood. Bull Insectology. 2015;68:321-7.

44. Kačániová M, Gasper J, Terentjeva M. Antagonisticeffect of gut microbiota of honeybee (Apis mellifera) against causative agent of American foulbrood Paenibacilluslarvae. J Microbiol Biotechnol Food Sci. 2020;9:478-81.

45. Jaouani I, MSAbbassi V, Alessandria J, Bouraoui R, Ben Salem HKilani, et al. High inhibition of Paenibacillus larvae and Listeria monocytogenes by Enterococcus isolated from different sources in Tunisia and identification of their bacteriocin genes. Lett Appl Microbiol. 2014;59:17-25.

46. Alippi AM, Francisco JReynaldi. Inhibition of the growth of Paenibacillus larvae, the causal agent of American foulbrood of honeybees, by selected strains of aerobic spore-forming bacteria isolated from apiarian sources. J Invertebr Pathol. 2006;91:141-6.

47. Looney WJ, Narita M, Mühlemann K. Stenotrophomonas maltophilia:an emerging opportunist human pathogen. Lancet Infect Dis. 2009;9:312-23.

48. Ryan RP, Monchy S, Cardinale M, Taghavi S, Crossman L, Avison MB, Berg G, et al. The versatility and adaptation of bacteria from the genus Stenotrophomonas. Nat Rev Microbiol. 2009;7:514-25. 
49. Indiragandhi P, Anandham R, Madhaiyan M, Poonguzhali S, Kim GH, Saravanan VS, Sa T. Cultivable bacteria associated with larval gut of prothiofos resistant, prothiofos susceptible and field-caught populations of diamondback moth, Plutella xylostella and their potential for, antagonism towards entomopathogenic fungi and host insect nutrition. J Appl Microbiol. 2007;103:2664. - 2675.

50. Morales-Jiménez J, Zúñiga G, Hugo C. Ramírez-Saad, and César Hernández-Rodríguez. Gutassociated bacteria throughout the life cycle of the bark beetle Dendroctonus rhizophagus Thomas and Bright (Curculionidae: Scolytinae) and their cellulolytic activities. Microb Ecol. 2012;64:268-78.

51. Sevim A. CihanGökçe, Zeynep Erbaş,FilizÖzkan. Bacteria from Ips sexdentatus (Coleoptera: Curculionidae) and their biocontrol potential. J Basic Microbiol. 2012;52:695-704.

52. Hughes GL, RaygozaGaray JA, Koundal V, Rasgon JL, Mwangi MM. Genome sequence of Stenotrophomonas maltophilia strain SmAs1, isolated from the Asian malaria mosquito Anopheles stephensi. Genome Announc. 2016;4:e00086-16.

53. Naaz N, Choudhary JS, Prabhakar CS, Moanaro, Maurya S. Identification and evaluation of cultivable gut bacteria associated withpeach fruit fly, Bactrocera zonata (Diptera: Tephritidae). Phytoparasitica. 2016;44:165-76.

54. Gandotra S, Kumar A, Naga K, Bhuyan PM, Gogoi DK, Sharma K. S Subramanian. "Bacterial community structure and diversity in the gut of the muga silkworm, Antheraea assamensis (Lepidoptera: Saturniidae), from India. Insect mol Biol. 2018;27:603-19.

55. Kang W-N, Fu K-Y, Guo W-C, Li G-Q. Complete genome sequence of Stenotrophomonas maltophilia strain CPBW01, isolated from the wings of the Colorado potato beetle in Xinjiang, China. Microbiol Resour Announc. 2020;9:25.

56. Shamim G, Sharma KK, Ramani R. Isolation and identification of culturable bacteria from honeydew of Indian lac insect, Kerria lacca (Kerr) (Hemiptera: Tachardiidae). Meta Gene. 2019;19:10-4.

57. Moraes AP, Rodrigues. Sandy Sampaio Videira, Vânia Rita Elias Pinheiro Bittencourt, Avelino José Bittencourt. Antifungal activity of Stenotrophomonas maltophilia in Stomoxys calcitrans larvae. Rev Bras Parasitol Vet. 2014;23:194-9.

58. Zhou F, Wu X, Xu L, Guo S, Chen G. Xinjian Zhang. Repressed Beauveria bassiana infections in Delia antiqua due to associated microbiota. Pest Manag Sci. 2019;75:170-9.

59. Olofsson TC, Ėile B, Markowicz P, Lindholm C, Larsson L. Alejandra Vásquez. Lactic acid bacterial symbionts in honeybees-an unknown key to honey's antimicrobial and therapeutic activities. Int Wound J. 2016;13:668-79.

60. Ayo K, Fasasi. Microbiota of honeybees, Apis melliferaAdansonii (Hymenoptera: Apidae) from selected ecozones, South West Nigeria. Pak J Biol Sci. 2018;21:232-8.

\section{Figures}



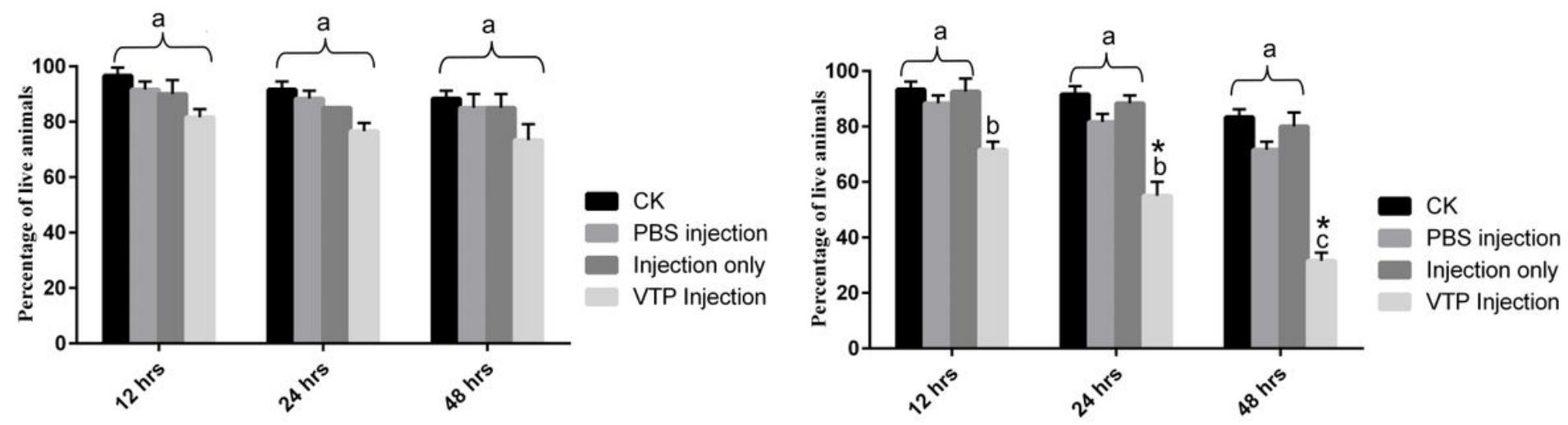

\section{Figure 1}

The mortality rates of the VTP injected or PBS injected or needle puncture only or uninjected A. mellifera and $A$. cerana larvae after $12 \mathrm{~h}, 24 \mathrm{~h}$, and $48 \mathrm{~h}$. Asterisks above bars indicate significant differences between the treatment and the corresponding control. 


\section{M}

\section{0 kDa}

$66.2 \mathrm{kDa}$

$45.0 \mathrm{kDa}$ $35.0 \mathrm{kDa}$

\section{$25.0 \mathrm{kDa}$}

\section{$18.4 \mathrm{kDa}$}

14. kDa

\section{Figure 2}

Expression profile analyses of VTP gene from V. destructor. Control, the crude extracts from the bacterial pellets without isopropyl $\beta$-D-1-thiogalactopyranoside (IPTG) induction. Purified, the recombinant VTP expressed in E. coli BL-21 (DE-3) and purified using complete His-Tag purification system. Protein molecular weight standards are used as size markers. M: Marker, I: IPTG induced VTP, C: Control, P: Purified VTP. 

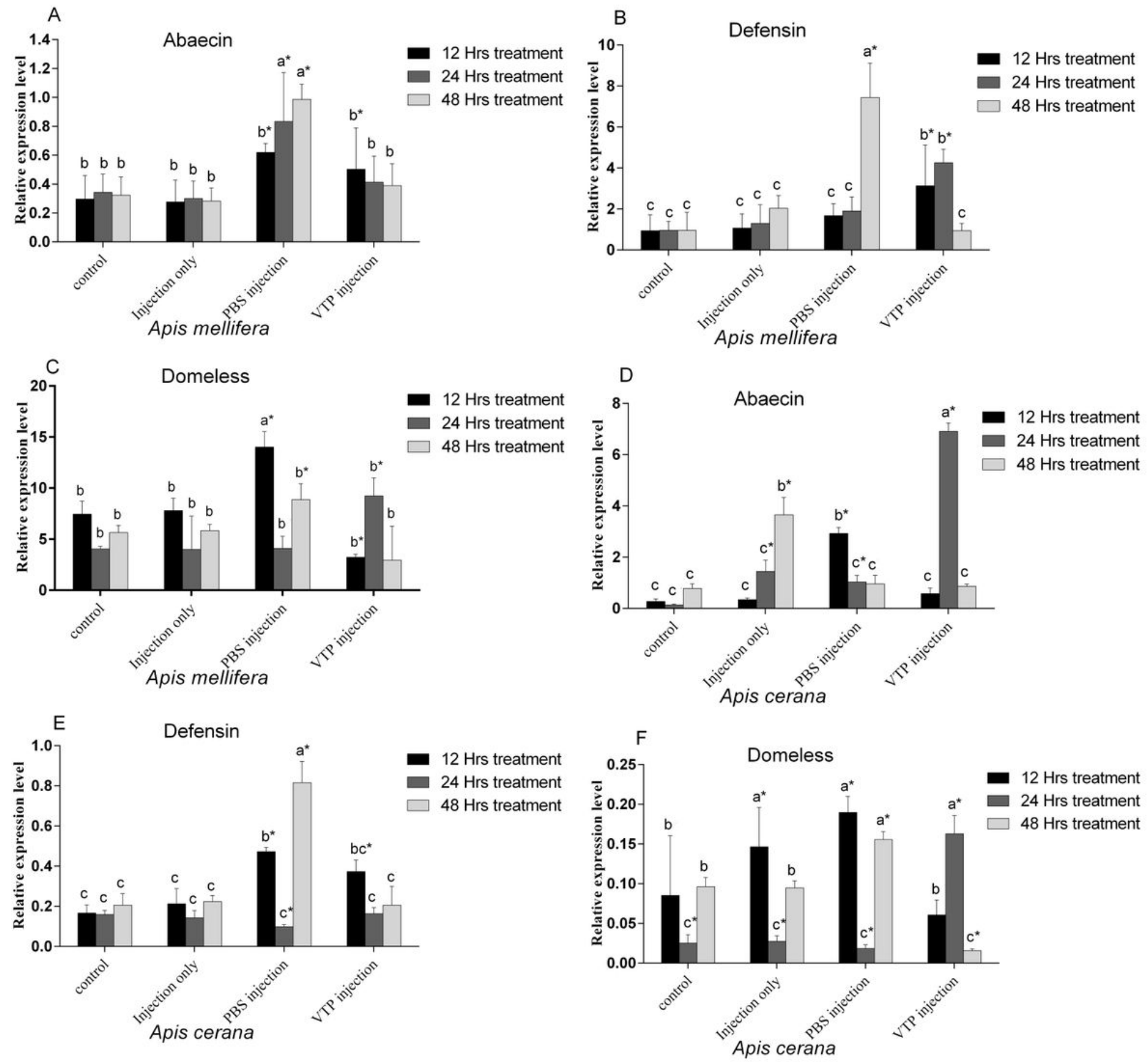

Figure 3

Relative expression of abaecin, defensin, and domeless in A. mellifera and A. ceranatreated with VTP, PBS and needle puncture. Different letters on the bars indicate that the means are significantly different among treatments according to the Tukey's test. Asterisks above bars indicate significant differences between the treatment and the corresponding control $(P<0.05)$. 


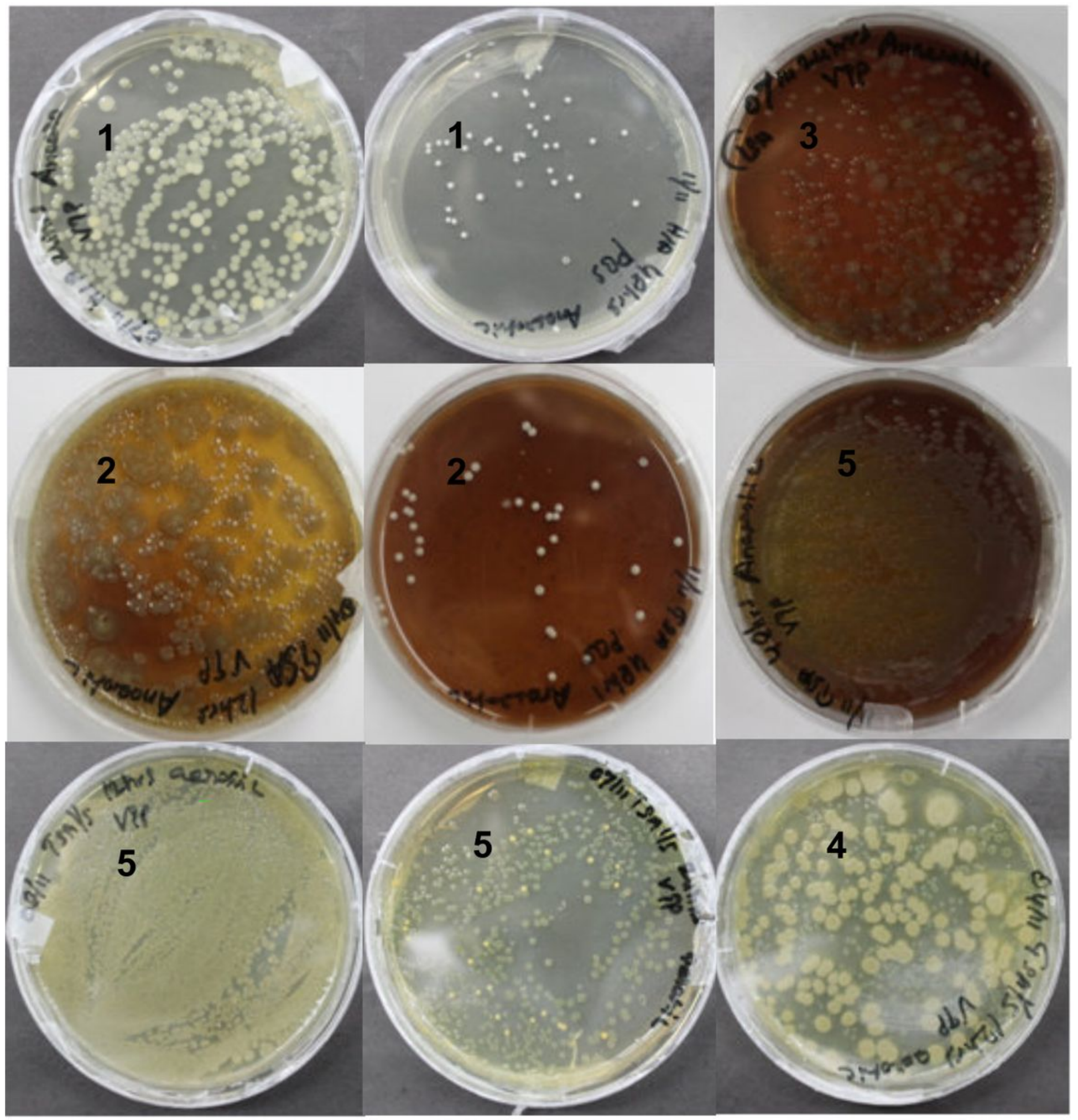

Figure 4

The bacterial species were isolated from different plates (TSA, HIA, and PDA) in both anaerobic and aerobic conditions from the hemolymph of A.cerana and A. mellifera.1. Enterococcus faecalis, 2. Staphylococcus cohnii, 3. Stenotrophomonas maltophilia, 4. Staphylococcus aureus, 5. Bacillus cereus 